\title{
BMJ Open Treatment for paediatric chronic fatigue syndrome or myalgic encephalomyelitis (CFS/ME) and comorbid depression: a systematic review
}

\author{
Maria E Loades, ${ }^{1}$ Elizabeth A Sheils, ${ }^{1}$ Esther Crawley $^{2}$
}

To cite: Loades ME, Sheils EA, Crawley E. Treatment for paediatric chronic fatigue syndrome or myalgic encephalomyelitis (CFS/ME) and comorbid depression: a systematic review. BMJ Open 2016;6: e012271. doi:10.1136/ bmjopen-2016-012271

- Prepublication history and additional material is available. To view please visit the journal (http://dx.doi.org/ 10.1136/bmjopen-2016012271).

Received 13 April 2016 Revised 27 July 2016 Accepted 28 July 2016

\section{CrossMark}

\section{${ }^{1}$ Department of Psychology, University of Bath, Bath, UK ${ }^{2}$ School of Social and Community Medicine, University of Bristol, Bristol, UK}

\section{Correspondence to} Dr Maria E Loades; m.e. loades@bath.ac.uk

\section{ABSTRACT}

Objectives: At least $30 \%$ of young people with chronic fatigue syndrome/myalgic encephalomyelitis (CFS/ME) also have symptoms of depression. This systematic review aimed to establish which treatment approaches for depression are effective and whether comorbid depression mediates outcome.

Setting: A systematic review was undertaken. The search terms were entered into MEDLINE, EMBASE, Psyclnfo and the Cochrane library.

Participants: Inclusion and exclusion criteria were applied to identify relevant papers. Inclusion criteria were children age $<18$, with $\mathrm{CFS} / \mathrm{ME}$, defined using CDC, NICE or Oxford criteria, and having completed a valid assessment for depression.

Results: 9 studies were identified which met the inclusion criteria, but none specifically tested treatments for paediatric CFS/ME with depression and none stratified outcome for those who were depressed compared with those who were not depressed. There is no consistent treatment approach for children with CFS/ME and comorbid depression, although cognitivebehavioural therapy for CFS/ME and a multicomponent inpatient programme for CFS/ME have shown some promise in reducing depressive symptoms. An antiviral medication in a small scale, retrospective, uncontrolled study suggested possible benefit.

Conclusions: It is not possible to determine what treatment approaches are effective for depression in paediatric CFS/ME, nor to determine the impact of depression on the outcome of CFS/ME treatment. Young people with significant depression tend to have been excluded from previous treatment studies.

\section{BACKGROUND}

Chronic fatigue syndrome (CFS)/myalgic encephalomyelitis (ME) in young people are common and disabling. It has a significant impact on a young person's functioning, including school attendance ${ }^{1}$ with approximately half of young people with CFS/ME being bedbound at some stage of their illness, and missing, on average, 1 year of

\section{Strengths and limitations of this study}

- A systematic approach was taken, which aimed to identify the highest quality evidence available.

- Two reviewers independently completed the screening and data extraction process, and a third reviewer arbitrated when there was a lack of consensus.

- Articles in foreign languages were included so these results have wide applicability.

- Grey literature and unpublished material were not included.

- A formal quality assessment of the observational studies was not undertaken.

school. ${ }^{2}$ The estimated prevalence of paediatric $\mathrm{CFS} / \mathrm{ME}$ is between $1 \%$ and $2.4 \%$ depending on the methodology and diagnostic criteria used. ${ }^{3}{ }^{4}$ There are a number of recognised and widely accepted diagnostic criteria for CFS/ME, including the Centers for Disease Control and Prevention (CDC) criteria, also known as the Fukuda definition, ${ }^{5}$ the Oxford $^{6}$ criteria and the criteria defined by the National Institute for Health and Care Excellence $^{7}$ (table 1). In summary, to meet a diagnosis of CFS/ME, these criteria require the presence of recurrent or persistent fatigue which is debilitating, has lasted for at least $3^{7}$ or 6 months ${ }^{5}$ in duration but is not lifelong, is not explained by ongoing exertion, is not alleviated by rest, is not explained by other conditions (including depression) and has a substantial impact on activity. ${ }^{8}$

Although the diagnosis of CFS/ME cannot be made if significant depression is the cause of the fatigue, a diagnosis can be made in the presence of comorbid depression which does not fully explain the disabling fatigue. At least $30 \%$ of children with CFS/ME have symptoms indicative of depression ${ }^{9}{ }^{10}$ which is significantly higher than the prevalence of depression in the healthy population of 


\begin{tabular}{|c|c|c|c|c|}
\hline & Oxford criteria $^{6}$ & CDC $_{\text {criteria }^{5}}$ & Canadian criteria $^{35}$ & NICE criteria $^{7}$ \\
\hline $\begin{array}{l}\text { Principal } \\
\text { symptom }\end{array}$ & Fatigue & Fatigue & Fatigue & Fatigue \\
\hline $\begin{array}{l}\text { Other } \\
\text { symptoms }\end{array}$ & Myalgia, mood, sleep disturbance & $\begin{array}{l}\text { At least four of: sore throat, tender } \\
\text { lymph nodes, muscle pain, joint } \\
\text { pain, headaches, unrefreshing } \\
\text { sleep, postexertional malaise, } \\
\text { impaired memory or concentration }\end{array}$ & $\begin{array}{l}\text { Postexertional malaise and/or } \\
\text { postexertional fatigue, unrefreshing } \\
\text { sleep or sleep disturbance, pain. } \\
\text { Cognitive dysfunction }\end{array}$ & $\begin{array}{l}\text { Malaise, headaches, sleep } \\
\text { disturbances, difficulties with } \\
\text { concentration and muscle pain and/ } \\
\text { or joint pain, painful lymph nodes, } \\
\text { sore throat, dizziness and/or nausea, } \\
\text { and palpitations with no identifiable } \\
\text { heart problem }\end{array}$ \\
\hline Onset & Definite onset but not life long & $\begin{array}{l}\text { Of new or definite onset } \\
\text { (not lifelong) }\end{array}$ & Not stated & New, persistent and/or recurrent \\
\hline Duration & $\begin{array}{l}\text { Minimum of } 6 \text { months, for } \geq 50 \% \text { of } \\
\text { the time }\end{array}$ & $\geq 6$ months. Persistent or relapsing & $\begin{array}{l}\geq 3 \text { months in a child or young } \\
\text { person. Persistent or reoccurring }\end{array}$ & $\begin{array}{l}\geq 3 \text { months in a child or young } \\
\text { person }\end{array}$ \\
\hline $\begin{array}{l}\text { Impact on } \\
\text { functioning }\end{array}$ & $\begin{array}{l}\text { Severe, disabling. Impacts on physical } \\
\text { and mental functioning }\end{array}$ & $\begin{array}{l}\text { Results in a substantial reduction in } \\
\text { occupational, educational, social or } \\
\text { personal functioning }\end{array}$ & $\begin{array}{l}\text { Results in substantial reduction in } \\
\text { previous levels of educational, social } \\
\text { and personal functioning }\end{array}$ & $\begin{array}{l}\text { Substantial reduction in activity } \\
\text { levels }\end{array}$ \\
\hline Exclusions & $\begin{array}{l}\text { Medical conditions known to result in } \\
\text { ongoing fatigue. Current diagnosis of } \\
\text { schizophrenia, manic depressive } \\
\text { illness, substance abuse, eating } \\
\text { disorder or organic brain disease }\end{array}$ & $\begin{array}{l}\text { Fatigue is not substantially } \\
\text { alleviated by rest, and is not the } \\
\text { result of ongoing exertion. Fatigue } \\
\text { is clinically evaluated and } \\
\text { unexplained }\end{array}$ & $\begin{array}{l}\text { Fatigue is clinically evaluated and } \\
\text { unexplained. } \\
\text { Current psychiatric conditions that } \\
\text { may explain the presence of chronic } \\
\text { fatigue, including schizophrenia or } \\
\text { psychotic disorders, bipolar disorder, } \\
\text { alcohol or substance abuse, anorexia } \\
\text { nervosa or bulimia nervosa and } \\
\text { depressive disorders }\end{array}$ & $\begin{array}{l}\text { Fatigue not explained by other } \\
\text { conditions. The diagnosis of CFS/ } \\
\text { ME should be reconsidered if none } \\
\text { of the following key features are } \\
\text { present: postexertional fatigue or } \\
\text { malaise, cognitive difficulties, sleep } \\
\text { disturbance and chronic pain }\end{array}$ \\
\hline Subtypes & $\begin{array}{l}\text { Two syndromes: } \\
\text { Chronic fatigue syndrome (CFS) } \\
\text { Postinfectious fatigue syndrome } \\
\text { (PIFS) }\end{array}$ & None specified & None specified & None specified \\
\hline
\end{tabular}

Table 1 Diagnostic criteria for CFS/ME

symptom

Other

Myalgia, mood, sleep disturbance leep, postexertional malaise

Of new or definite onset

(not lifelong)

Fatigue is not substantially is clinically evaluated and illness, substance abuse, eating illness, substance abuse, eating (PIFS) 
between $0.92 \%{ }^{11}$ and $5 \% .^{12}$ Rates of depression in children with CFS/ME are also higher than the rates of depression in children with other chronic illnesses, for example, cystic fibrosis. ${ }^{13}$

The impact of having a comorbid mood disorder for young people with CFS/ME is unclear. Depression during adolescence in the normal population increases the risk of subsequent depression, interpersonal difficulties and suicide in adulthood. ${ }^{14}$ While the long-term impact of depression in paediatric CFS/ME specifically is not known, cross-sectional studies have shown that young people with CFS/ME and comorbid depression are also more functionally disabled with worse fatigue and more pain compared with those without depression. ${ }^{10}$ Comorbid depression in adults with CFS/ME has been associated with a worse prognosis in some clinical trials, ${ }^{15-19}$ but not in others. ${ }^{20-22}$ It is plausible that comorbid paediatric depression in CFS/ME may impact on treatment outcome, but this has yet to be investigated.

Despite the recognised comorbidity and clear guidance that children/young people with CFS/ME should be screened and treated for depression, ${ }^{72}$ little is known about the efficacy and effectiveness of treatments for paediatric CFS/ME with comorbid depression, and the impact of the comorbid depression on recovery in CFS/ME. This review aims to synthesise the existing evidence regarding treatments for paediatric CFS/ME and comorbid depression by addressing the following questions:

1. What does the existing quantitative and qualitative literature tell us about treatment approaches for depression in children with CFS/ME?

2. What is the outcome for children with CFS/ME who are depressed compared with children who are not depressed?

3. Does the outcome for children with CFS/ME and comorbid depression vary between studies? Do particular treatment approaches have different outcomes?

\section{METHODS}

This review was registered on Prospero in February 2015, registration numberCRD42015016813. The protocol is available from http://www.crd.york.ac.uk/PROSPERO/ display_record.asp?ID=CRD42015016813.

\section{Data sources and search strategy}

The search strategy was designed to identify studies examining depression in children or young people $(<18)$ with CFS/ME. MEDLINE, EMBASE, PsycInfo and the Cochrane library were searched using search terms developed in collaboration with an information specialist, designed to include the concepts 'paediatric', 'CFS/ ME' and 'depression' (details of search terms used available via http://dx.doi.org/10.15125/BATH-00127 and as an online supplementary file). Citation lists of included articles were hand-searched. Searches were carried out in February 2015.
Study selection (inclusion and exclusion criteria)

Titles and abstracts of all articles were assessed for inclusion by two reviewers (MEL and EAS) and conflicts discussed and resolved. Articles for possible inclusion were reviewed in full and independently assessed for inclusion by two reviewers (MEL and EAS), with all conflicts discussed and reviewed by a third reviewer (EC).

Inclusion criteria were children age $<18$, with CFS/ $\mathrm{ME}$, defined using CDC criteria, ${ }^{5} \mathrm{NICE}^{7}$ or Oxford criteria ${ }^{6}$ and having completed a valid assessment for depression. This review was limited to studies with young people (age <18 years) from 1991 onwards as this is when the Oxford diagnostic criteria were published.

Studies of children who were fatigued due to other causes and studies where chronic fatigue was not defined using one of the above criteria were excluded. Studies of predominantly adult samples, where the data were not separable for the $<18$ years, were also excluded.

Observational studies and clinical trials (randomised or quasi-randomised) of children with CFS/ME where symptoms of depression were measured were included, as were qualitative studies that reported on the treatment of depression in children with CFS/ME. The outcome data of interest was a change in depression and/or fatigue on psychometrically validated assessments or validated diagnostic interviews, and studies presenting such data, whether there was an intervention or not, were included.

Studies published in foreign languages were considered for inclusion. Where English language abstracts were not available, or where the titles and abstracts indicated that the study potentially met the inclusion criteria and merited full-text review, the papers were translated by native speakers to determine whether they met the inclusion criteria. None of these papers met the full inclusion criteria.

\section{Data extraction and appraisal}

Data extraction was completed independently by two reviewers (MEL and EAS) using a purpose-designed data extraction form, designed to capture the following aspects: details of the setting of the study, how children were recruited for the study, date of the study, participant characteristics (including age and gender), the study design, the CFS/ME definition used, how depression was assessed, definition of response and the treatment/intervention offered and outcomes.

\section{Data synthesis}

If sufficient data were available, a meta-analysis would have been conducted. The interventions were heterogeneous and the data were across a range of outcome measures which precluded this; therefore, a narrative review was carried out.

\section{Quality assessment}

An assessment of study methodological quality was undertaken for the included randomised controlled trials (RCTs) using the Cochrane risk of bias assessment tool. ${ }^{24-26}$ 


\section{RESULTS}

The systematic review identified 362 papers, with 1 further paper identified by hand searching reference lists of included articles (figure 1). Of these 363 papers, 96 were included at full review, with the remainder excluded at the screening stage. Of the 363 papers, 8 were foreign language articles $(\mathrm{N}=8 ; 2$ French, 1 Catalan, 1 Russian, 2 Japanese, 1 Dutch, 1 Greek). Nine studies met the inclusion criteria for the review.

\section{Characteristics of included studies \\ Quality assessment}

Of the nine studies that met the inclusion criteria, there was one RCT. ${ }^{27}$ The Cochrane risk of bias assessment tool was applied to this study (table 2). In summary, there was a low risk of bias in some domains, but a high risk of bias, or an uncertain risk of bias in others.

\section{Study design}

In summary, one included study was an RCT, which compared two variations of the physical exercise intervention of a multicomponent treatment programme in an inpatient setting. The remaining eight studies were observational. Of these, six studies described outcome after outpatient (three investigating CBT and one antiviral medication) or inpatient (two studies investigating a multicomponent programme) treatment. Two more studies were epidemiological studies. Further details of the study designs are described below and in tables 3 (methodology) and 4 (findings). All studies, including the RCT, had relatively small sample sizes, with the smallest including 4 patients with CFS/ME, and the largest including 63 patients, of whom 52 were followed up.

Three studies evaluated the outcomes of CBT for CFS/ME. Chalder et $a l^{28}$ administered a CBT-based outpatient rehabilitation programme focused on remediating CFS/ME of up to 15 hourly face-to-face sessions. Lloyd et $a l^{29}$ offered a less intensive intervention of CBT-based guided self-help, focused on remediating $\mathrm{CFS} / \mathrm{ME}$ and also emotional symptoms where appropriate, via six telephone sessions, of $30 \mathrm{~min}$ in duration, at fortnightly intervals. Kawatani $e t a l^{30}$ offered, on average, five sessions of CBT over a 6-month period, combined with pharmacotherapy (6 of the 19 patients were prescribed SSRIs with or without other medications, 5 patients received an antihypotensive medication, midodrine hydrochloride, 4 received other medications and 4 received no medication).

Three studies, including an RCT, evaluated the outcomes of a 4-week inpatient programme, focused on
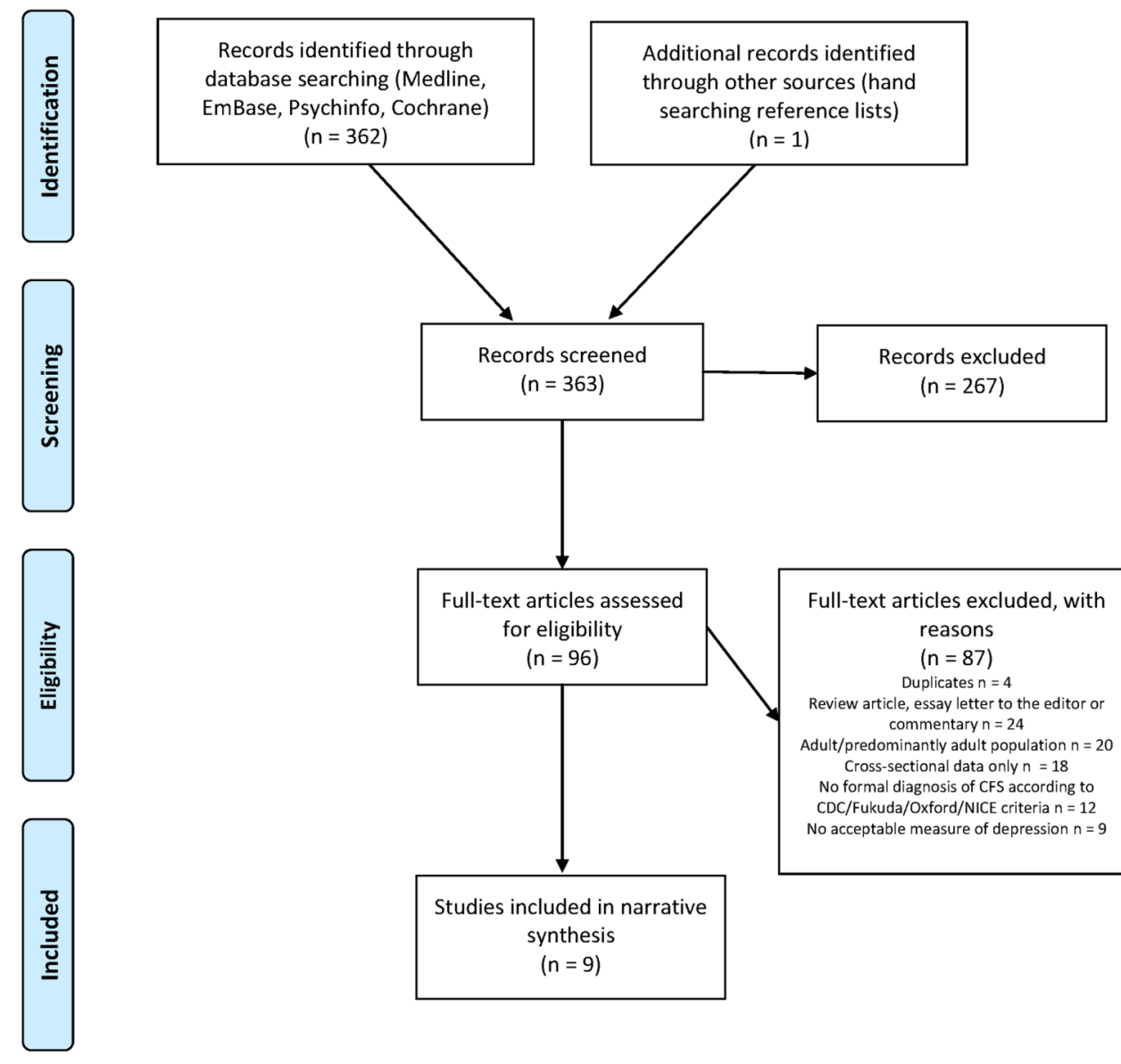
Full-text articles excluded, with reasons $(n=87)$ Duplicates $n=4$ Review article, essay letter to the editor or commentary $n=24$ Adult/predominantly adult population $n=20$ Cross-sectional data only $n=18$ No formal diagnosis of CFS according to CDC/Fukuda/Oxford/NICE criteria $n=12$ No acceptable measure of depression $n=9$

Figure 1 Flow chart for systematic review based on PRISMA: Preferred Reporting Items for Systematic reviews and Meta-Analyses. ${ }^{49}$ 
Table 2 Risk of bias assessment for Gordon et $a^{{ }^{7}}$ trial

\begin{tabular}{|c|c|c|}
\hline Domain & Description & $\begin{array}{l}\text { Review author's judgement } \\
\text { regarding risk of bias }\end{array}$ \\
\hline $\begin{array}{l}\text { Random sequence } \\
\text { generation }\end{array}$ & Drawing a piece of paper out of an envelope & Low risk \\
\hline Allocation concealment & Unclear & Uncertain risk of bias \\
\hline $\begin{array}{l}\text { Blinding of participants } \\
\text { and personnel }\end{array}$ & Not possible & High risk \\
\hline $\begin{array}{l}\text { Blinding of outcome } \\
\text { assessment }\end{array}$ & $\begin{array}{l}\text { Blinded assessor completed baseline and follow-up } \\
\text { assessments }\end{array}$ & Low risk \\
\hline $\begin{array}{l}\text { Incomplete outcome } \\
\text { data }\end{array}$ & $\begin{array}{l}\text { Missing data points substituted with the last known measure for } \\
\text { each outcome. Intention to treat analysis using MANOVA }\end{array}$ & Low risk \\
\hline Selective reporting & Insufficient information & Uncertain risk of bias \\
\hline Other sources of bias & Unclear & Uncertain risk of bias \\
\hline
\end{tabular}

graded exercise using hydrotherapy and physiotherapy, school attendance and psychiatric input as required. The RCT specifically compared two variations of physiotherapy, aerobic exercise and resistance training, within this programme. These studies were all small in sample size, and due to the multidisciplinary and multicomponent nature of the intervention (which included psychological therapy where indicated with no further details specified about this), it is not possible to draw any conclusions about what the key components of the approach may have been. The studies by Gordon and Lubitz $^{31}$ and Gordon et $a l^{27}$ are also limited by a lack of follow-up data postdischarge.

One study was a retrospective case series of an antiviral medication (outpatient) with a small sample size $(\mathrm{N}=15)$ and variable length of intervention (ranging from 3 to 60 months). This study is further limited by the lack of a comparator or control condition, and the uncontrolled nature of this study, which does not report on other interventions (eg, psychological input) which the patient may have had concurrently. There are also considerable missing data, particularly in regard to depression outcomes, which could bias the study findings.

Two studies did not offer any active intervention. Rimes $e t a l^{32}$ conducted a prospective study of a random sample of British adolescents $(n=842)$ from the general population who were assessed at baseline and $~ 4-$ 6 months later as part of the Office for National Statistics study of mental health in children. van de Putte $e t a l^{33}$ undertook a longitudinal study to explore alexithymia (the inability to identify and/or describe one's emotions) in paediatric CFS/ME. The research aimed to establish whether alexithymia was a prognostic factor for recovery from CFS/ME. As part of this study, they sought to establish the number of participants who had 'recovered' from CFS/ME at 18 months $(n=40)$, where recovery is defined as scoring within 2 SDs of the average fatigue score within a population of healthy adolescents on the Subjective Fatigue Subscale of the Checklist Individual Strength (CIS-20). CFS/ME patients were compared with healthy controls $(n=36)$ at baseline. No differences in recovery were evident between those adolescents with alexithymia compared with those who were not alexithymic.

Only one study stratified their findings by depressed versus non-depressed participants, ${ }^{34}$ and no studies stratified their results by the severity of depression (mild/moderate/severe).

Of the included studies, no studies were specifically aimed at treating depression in the context of paediatric CFS/ME. Thus, it appears that approaches commonly used for CFS/ME are used for this subgroup of patients without any particular adaptations. At the current time, evidence of efficacy or effectiveness for specific treatments tailored to the subgroup of patients with depression in the context of paediatric CFS/ME does not exist.

\section{The effectiveness of interventions in reducing depression symptoms}

Cognitive-behavioural therapy

The outcomes of CBT for CFS/ME varied across the three studies included. Chalder et $a t^{28}$ found that, in those 20 patients who completed treatment, depression, fatigue, functioning and social adjustment significantly improved following their relatively intensive CBT programme. Lloyd et $a t^{29}$ showed that a less intensive CBT intervention resulted in a significant change in fatigue and school attendance, with improvements in depression, impairment and adjustment in the 52 patients retained in the study at 6-month follow-up. However, Kawatani et $a l^{30}$ assessed depressive symptomatology in 19 patients at baseline, and, on average, most of them were in the mildly depressed range. In this group, they did not find a significant improvement in fatigue at 6-month follow-up; mood was not reassessed. This study applied the Jason et $a l^{35}$ diagnostic criteria, which defines depressive disorders in the exclusionary criteria, meaning that all those who were clinically depressed would have been excluded from the study.

\section{Multicomponent inpatient programme}

All three studies ${ }^{27} 3136$ evidence an improvement in mood post-treatment (which applied to both arms of 


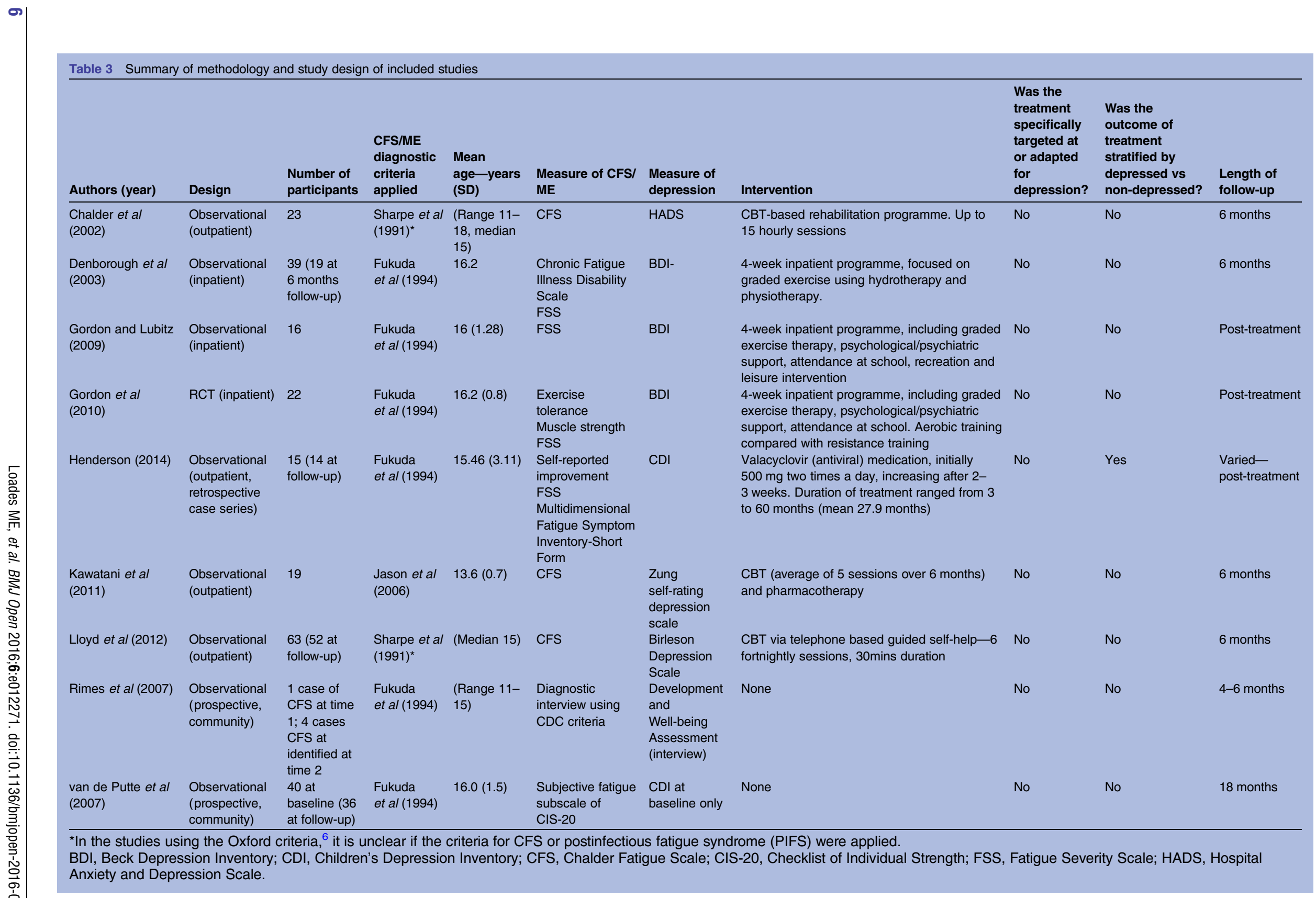


Table 4 Summary of outcomes for depressive symptoms and other relevant findings for included studies

\begin{tabular}{|c|c|c|c|c|c|}
\hline Authors (year) & $\begin{array}{l}\text { Measure of } \\
\text { depression }\end{array}$ & Pretreatment & $\begin{array}{l}\text { Post-treatment (unless } \\
\text { otherwise stated) }\end{array}$ & $\begin{array}{l}\text { Statistical analysis of } \\
\text { change in depressive } \\
\text { symptomatology }\end{array}$ & Summary of other relevant findings \\
\hline $\begin{array}{l}\text { Chalder et al } \\
\text { (2002) }\end{array}$ & HADS & Mean 8.4 (IQR 5.7-11) & $\begin{array}{l}\text { 6-month follow-up } \\
\text { Mean } 3 \text { (IQR 3-5) }\end{array}$ & $\begin{array}{l}\text { Wilcoxon signed-ranks test } \\
-3.33 \text { (two-tailed } \\
\text { significance } 0.00 \text { ) }\end{array}$ & $\begin{array}{l}\text { All } 20 \text { treatment completers returned to school at } \\
6 \text { months follow-up, with } 95 \% \text { attending full time. } \\
\text { Depression significantly improved, as did social } \\
\text { adjustment }\end{array}$ \\
\hline $\begin{array}{l}\text { Denborough } \\
\text { et al (2003) }\end{array}$ & BDI & Mean score 21 & Mean score 15 & $\begin{array}{l}\text { Improvement } p<0.001 \\
\text { Maintained at } 6 \text {-month } \\
\text { follow-up }(p<0.038)\end{array}$ & $\begin{array}{l}\text { On discharge, the mean depression score significantly } \\
\text { better than on admission. Also significant improvement in } \\
\text { Chronic Fatigue Illness Disability score and significant } \\
\text { decrease in FSS score (maintained at } 6 \text {-month follow-up). } \\
\text { Achenbach/Youth Self-Report scores improved } \\
\text { significantly by discharge, but returned to above } \\
\text { admission levels at } 6 \text { months }\end{array}$ \\
\hline $\begin{array}{l}\text { Gordon and } \\
\text { Lubitz (2009) }\end{array}$ & $\mathrm{BDI}$ & Mean 19.88 SD 8.62 & Mean 11.44 SD 10.98 & $\begin{array}{l}\text { Paired t-test } p \text { value } 0.001 \\
\text { sig } 0.008\end{array}$ & $\begin{array}{l}\text { Significant improvement in BDI scores, Fatigue Severity } \\
\text { scores }\end{array}$ \\
\hline $\begin{array}{l}\text { Gordon et al } \\
\text { (2010) }\end{array}$ & $\mathrm{BDI}$ & $\begin{array}{l}\text { Resistance Arm } \\
\text { Pretreatment } 20.9 \pm 11.3 \\
\text { Aerobic arm } \\
\text { Pretreatment } 16.4 \pm 4.3\end{array}$ & $\begin{array}{l}\text { Resistance arm } \\
\text { Post-treatment } 14.2 \pm 10.0 \\
\text { Aerobic arm } \\
\text { Post-treatment } 12.2 \pm 6.7\end{array}$ & $\begin{array}{l}\text { Resistance arm } \\
\text { Difference }-6.7 \pm 8.5 \\
\mathrm{p}=0.03 \\
\text { Aerobic arm } \\
\text { Difference }-4.2 \pm 4.8 \\
\mathrm{p}=0.002\end{array}$ & Significant improvement in BDI scores in both arms \\
\hline $\begin{array}{l}\text { Henderson } \\
\text { (2014) }\end{array}$ & CDI & $\begin{array}{l}\text { Mean score } 14 \pm 2.83 \text { ( } 4 \text { patients } \\
\text { with mood disorder, } 16.8 \pm 1.92) \\
\text { (11 patients without mood disorder } \\
12.73 \pm 2.00 \text { ) }\end{array}$ & Not stated & Not reported & $\begin{array}{l}\text { All patients reported at least } 80 \% \text { self-rated improvement. } \\
\text { Significant reduction in FSS, MSFI (all subscales) }\end{array}$ \\
\hline $\begin{array}{l}\text { Kawatani et al } \\
\text { (2011) }\end{array}$ & $\begin{array}{l}\text { Zung self-rating } \\
\text { depression scale }\end{array}$ & $53.3 \pm 6.7$ & Not stated & Not reported & $\begin{array}{l}\text { No significant change between baseline fatigue scores } \\
\text { and fatigue scores } 6 \mathrm{~m} \text { follow-up. Significant improvement } \\
\text { in performance status scores (self-reported impact on } \\
\text { functioning) }\end{array}$ \\
\hline $\begin{array}{l}\text { Lloyd et al } \\
\text { (2012) }\end{array}$ & $\begin{array}{l}\text { Birleson } \\
\text { Depression } \\
\text { Scale }\end{array}$ & $\begin{array}{l}\text { Baseline mean } 13.38 \text { (SD 4.76) } \\
\text { Pretreatment mean } 12.91 \text { (SD 5.57) }\end{array}$ & $\begin{array}{l}\text { Post-treatment mean } \\
\text { 10.98 (SD 5.35) } \\
\text { 3-month follow-up mean } \\
\text { 10.47 (SD 5.87) } \\
\text { 6-month follow-up mean } \\
9.22 \text { (SD 5.36) }\end{array}$ & $\begin{array}{l}\text { Multilevel modelling and } \\
\text { Wald tests } \\
\text { Treatment effect estimate at } \\
6 \text { months }-3.69(\mathrm{Cl}-5.17 \text { to } \\
-2.21) \\
\text { Significance (two-tailed) } \\
<0.001 \text {, effect size } 0.78\end{array}$ & $\begin{array}{l}\text { Significant change in fatigue and school attendance, with } \\
\text { improvements in depression, impairment and adjustment } \\
\text { at } 6 \text { months }\end{array}$ \\
\hline $\begin{array}{l}\text { Rimes et al } \\
(2007)\end{array}$ & & $\begin{array}{l}3 \text { of } 4 \text { had at least } 1 \text { psychiatric } \\
\text { diagnosis at baseline }\end{array}$ & $\begin{array}{l}4 \text { participants developed } \\
\text { CFS/ME at follow-up } \\
\text { (4-6 months) }\end{array}$ & Not reported & $\begin{array}{l}\text { Of the } 4 \text { participants who developed CFS/ME over the } \\
\text { follow-up period, } 3 \text { of } 4 \text { had at least } 1 \text { psychiatric } \\
\text { diagnosis at baseline, } 3 \text { had reported being 'much more } \\
\text { tired and worn out than usual over the last month' at time } \\
1,2 \text { participants had frequent headaches at time } 1,1 \text { also } \\
\text { had sleep problems and postexertional malaise at time } 1\end{array}$ \\
\hline $\begin{array}{l}\text { Van de Putte } \\
\text { et al (2007) }\end{array}$ & CDI & Mean score at baseline 11.7 SD 6.1 & Not stated & Not reported & $\begin{array}{l}47 \% \text { of adolescents 'fully recovered' (below score ie, } \\
\text { mean plus } 2 \text { SD of subjective fatigue distribution in health } \\
\text { adolescents). }\end{array}$ \\
\hline
\end{tabular}

Aerobic arm

$12.73 \pm 2.00)$

Kawatani et al Zung self-rating depression scale

3 of 4 had at least 1 psychiatric diagnosis at baseline
Post-treatment (unless

6-month follow-up

Mean score 15

All 20 treatment completers returned to school at 6 months follow-up, with $95 \%$ attending full time. Depression significantly improved, as did social adjustment improvement in Chronic Fatigue IIIness Disability score and significant Achenbach/Youth Self-Report scores improved significantly by discharge, but returned to above admission levels at 6 months

Significant improvement in BDI scores, Fatigue Severity scores

Resistance arm Resistance arm

$\begin{array}{ll} & \mathrm{p}=0.03 \\ \text { Aerobic arm } & \text { Aerobic arm }\end{array}$

$\mathrm{p}=0.002$

Not reported

All patients reported at least $80 \%$ self-rated improvement. No significant change between baseline fatigue scores and fatigue scores $6 \mathrm{~m}$ follow-up. Significant improvemen functioning)

Significant change in fatigue and school attendance, with improvements in depression, impairment and adjustment 10.47 (SD 5.87) 6-month follow-up mean

Significance (two-tailed) $<0.001$, effect size 0.78

Not reported follow-up period, 3 of 4 had at least 1 psychiatric diagnosis at baseline, 3 had reported being 'much more tired and worn out than usual over the last month' at time 1,2 participants had frequent headaches at time 1, 1 also had sleep problems and postexertional malaise at time $47 \%$ of adolescents 'fully recovered' (below score ie, mean plus 2 SD of subjective fatigue distribution in health adolescents).

Anxiety and Depression Scale. 
the RCT), as well as a decrease in fatigue symptoms and an improvement in functioning. Denborough et $a l^{36}$ showed that improvements in mood and fatigue are maintained at 6-month follow-up, although parentalrated and self-reported internalising problems had escalated to above preadmission levels.

\section{Antiviral medication}

Henderson $^{34}$ presents separate data on the posttreatment scores of one subscale (emotional subscale) of the Multidimensional Fatigue Symptom Inventory-Short Form (MSFI-SF) for three patients who were diagnosed with mood disorder when compared with seven participants who were not diagnosed with mood disorder (data on this variable are missing for the remaining five patients in the study) at assessment for treatment with Valacyclovir. The length of treatment was variable (mean 27.9 months, range 3-60 months). Patients with a mood disorder had a mean pretreatment score on the emotional subscale of the MSFI of $13.00 \pm 6.16$ and a mean post-treatment score of $6.67 \pm 2.89$, when compared with patients without a mood disorder who had a pretreatment score of $8.40 \pm 2.76$ and a mean post-treatment score of 1.5 \pm 1.6 . Thus, depression symptoms decreased in depressed and non-depressed patients over the course of treatment. The remaining outcome data (self-rated improvement, sleep, school performance, Fatigue Severity Scale (FSS) scores, Fatigue Symptom Inventory (FSI), and the fatigue, physical, mental and vigour subscales of the MSFI) indicate significant improvements but are not stratified for the patients with and without mood disorder.

Epidemiological studies. Rimes et $a l^{22}$ found that four cases of CFS (according to CDC criteria) had developed at 6-month follow-up in their population sample, three of whom had had at least one psychiatric diagnosis at baseline. Furthermore, three cases had reported being more worn out than usual at time 1 . There was also one case of CFS diagnosed at baseline, although further information about follow-up assessments is not separately available for this participant. van de Putte et $a l^{33}$ found that $47 \%$ of the $36 \mathrm{CFS} / \mathrm{ME}$ participants in their longitudinal study had 'recovered' from CFS/ME at 18 months. At baseline, the CFS participants were found to have significantly higher depression scores on the Children's depression inventory (CDI) compared with healthy controls, although the mean CDI score in the CFS group still fell below the clinical cut-off for depressive disorder. The outcomes in terms of recovery are not stratified by depression severity.

\section{DISCUSSION}

Despite the high prevalence of depression in young people with CFS/ME, there is little evidence about the effectiveness of treatment for this population, and no specifically adapted treatments have been trialled in this population. In the studies included in this review, the mean depression scores of the participants tended to be below clinical cut-offs for depression pretreatment. Thus, the samples in treatment studies, in which potential participants with significant depression tend to be excluded, do not appear to be representative of those in clinical cohort studies, which have found a much higher prevalence of depression in paediatric CFS/ME. ${ }^{10}$ In these skewed samples, treatments aimed at remediating CFS/ME, including CBT and a multicomponent inpatient programme can result in improvements in mood.

The strengths of this review are that a systematic approach was taken, which sought to identify the highest quality evidence available. Furthermore, two reviewers independently completed the screening and data extraction procedures, with a third reviewer arbitrating when there were differences of opinion. Articles in foreign languages were included so these results are not limited to UK patients. However, a formal review of the quality of the observational studies was not undertaken. This would have been undertaken had those studies provided significant evidence to inform the review questions.

There is a lack of evidence to inform clinicians on how best to help young people with CFS/ME who are also low in mood, which is particularly surprising, given that psychological models of the perpetuation of chronic fatigue and disability include depression as part of the maintenance cycle. ${ }^{37}$ Cognitive-behavioural therapy, a multicomponent inpatient programme and antiviral medication are the interventions used in the included studies. CBT and the multicomponent inpatient programme are broadly consistent with the evidence-based guidelines from the National Institute for Health and Care Excellence for the management and treatment of $\mathrm{CFS} / \mathrm{ME}^{7}$ and the management and treatment of depression. ${ }^{38}$ The participants appear to have benefited from these interventions, including in terms of mood, although the data do not allow comparisons to be made about whether those who were low in mood benefited less, as much, or possibly more than those who were not low in mood. Larger sample sizes, with more separable data about those participants who are depressed versus those who are not depressed at baseline would enable further conclusions to be drawn about the effectiveness of these treatment approaches for those with comorbid depression.

The lack of evidence about what treatment approach is most effective with young people who have CFS/ME and depression is further compounded by contradictions within treatment approaches and the recommendations for the disorders separately. Certain recommendations made by NICE for the management of $\mathrm{CFS}^{7}$ contradict the recommendations for the management of depression. ${ }^{38}$ For example, exercising for up to three sessions, $45 \mathrm{~min}$ to an hour in duration of moderate exercise, per week for $10-12$ weeks $^{39}$ may be effective for depression but could exacerbate symptoms in patients with CFS/ME. Interventions for depression 
such as behavioural activation would be limited by the activity management approach advocated for managing the CFS/ME. ${ }^{7}$ Furthermore, standard cognitive therapy is cognitively demanding and may be beyond the capacity of a young person who is cognitively limited in attentional capacity and memory by fatigue. ${ }^{40}$

Similarly, the existing guidance and literature does not provide any clear direction about using medication. There is no known pharmacological treatment for CFS/ ME, although medications can be used for symptom management. ${ }^{7}$ In the current review, one study used antiviral medication with possible benefit, although this study was small scale, uncontrolled, retrospective and had a variable length of follow-up, and therefore, it is difficult to draw any firm conclusions about the findings. There is variable evidence about the efficacy of antidepressant medications (SSRIs) in young people with a primary diagnosis of depression; while antidepressants can result in improvements to young people's mood, ${ }^{41}{ }^{42}$ there are indications that SSRIs can increase suicidality. ${ }^{43}$ The NICE ${ }^{38}$ recommendation is that medication should only be offered in combination with a specific psychological therapy unless the latter is declined. Furthermore, there is currently no evidence about whether antidepressant medication is beneficial for young people with CFS and depression; in the current review, one paper did include SSRIs in combination with CBT, but only for a proportion of their sample, and outcome data were not separately presented for those with depression. ${ }^{30}$ Additionally, there is mixed evidence about the utility of antidepressant medication in adult CFS populations with some studies finding no effect of fluoxetine in comparison to placebo ${ }^{44} 45$ and others showing significant improvements in CFS/ME and depressive symptomatology in response to s-citalopram. ${ }^{46}$

It is notable that a number of the large-scale studies of recovery in paediatric CFS/ME such as the Dutch trials of FITNET ${ }^{47} 48$ do not appear to have specifically included low mood or depression as an outcome variable, although a broader well-being measure was included in this study and a specific measure of depression was used at the baseline assessment to exclude the most severely depressed young people. Furthermore, in these trials, and a number of other trials of treatments for paediatric CFS/ME, participants with psychiatric diagnoses are excluded. Therefore, uncertainty remains about how best to treat young people who have diagnosable depression in the context of paediatric CFS/ME.

\section{CONCLUSION}

This review has highlighted the relative lack of evidence regarding effective treatment for paediatric CFS/ME and comorbid depression. Given the levels of comorbidity, ${ }^{10}$ impact on functioning and potentially, impact on response to treatment, developing and trialling potentially efficacious and effective treatments for children and young people with CFS/ME and depression is a priority for future research.

Contributors MEL and EC conceptualised and designed the study. MEL and EAS carried out the data search and analysis. MEL drafted the manuscript. EC contributed to the analysis process by when there was uncertainty about decisions about whether studies met the inclusion criteria. EC reviewed and revised the manuscript. All authors reviewed and approved the manuscript prior to submission.

Funding This study was funded by donated Funds from the Royal National Hospital for Rheumatic Diseases (RNHRD) grant number RNP00267331143E. EC is funded by the NIHR (Senior Research Fellowship, SRF-2013-06-013).

Disclaimer This report is independent research. The views expressed in this publication are those of the authors(s) and not necessarily those of the NHS, The National Institute for Health Research or the Department of Health.

Competing interests EC is an unpaid medical advisor to the Association for young people with ME and the Sussex \& Kent ME/CFS Society.

Provenance and peer review Not commissioned; externally peer reviewed.

Data sharing statement This systematic review draws on published research only. No new data were collected or generated in undertaking this study.

Open Access This is an Open Access article distributed in accordance with the Creative Commons Attribution Non Commercial (CC BY-NC 4.0) license, which permits others to distribute, remix, adapt, build upon this work noncommercially, and license their derivative works on different terms, provided the original work is properly cited and the use is non-commercial. See: http:// creativecommons.org/licenses/by-nc/4.0/

\section{REFERENCES}

1. Crawley E, Sterne JA. Association between school absence and physical function in paediatric chronic fatigue syndrome/myalgic encephalopathy. Arch Dis Child 2009;94:752-6.

2. Garralda ME, Rangel L. Impairment and coping in children and adolescents with chronic fatigue syndrome: a comparative study with other paediatric disorders. J Child Psychol Psychiatry 2004;45:543-52.

3. Garralda ME, Chalder T. Practitioner review: chronic fatigue syndrome in childhood. J Child Psychol Psychiatry 2005;46:1143-51.

4. Mackenzie C, Wray A. Chronic fatigue syndrome in children and young people. Paediatr Child Health 2013;23:35-9.

5. Fukuda K, Straus SE, Hickie I, et al. The chronic fatigue syndrome: a comprehensive approach to its definition and study. Ann Intern Med 1994;121:953-9.

6. Sharpe MC, Archard LC, Banatvala JE, et al. A report-chronic fatigue syndrome: guidelines for research. $J R$ Soc Med 1991;84:118-21.

7. NICE. Chronic fatigue syndrome/myalgic encephalomyelitis (or encephalopathy): diagnosis and management of CFS/ME in adults and children. Excellence NIfHaC, 2007.

8. Reeves WC, Wagner D, Nisenbaum R, et al. Chronic fatigue syndrome-a clinically empirical approach to its definition and study. BMC Med 2005;3:19.

9. Knight S, Harvey A, Towns S, et al. How is paediatric chronic fatigue syndrome/myalgic encephalomyelitis diagnosed and managed by paediatricians? An Australian Paediatric Research Network Study. $J$ Paediatr Child Health 2014;50:1000-7.

10. Bould H, Collin SM, Lewis G, et al. Depression in paediatric chronic fatigue syndrome. Arch Dis Child 2013;98:425-8.

11. Ford T, Goodman R, Meltzer $\mathrm{H}$. The British child and adolescent mental health survey 1999: the prevalence of DSM-IV disorders. J Am Acad Child Adolesc Psychiatry 2003;42:1203-11.

12. Zhou X, Michael KD, Liu Y, et al. Systematic review of management for treatment-resistant depression in adolescents. BMC Psychiatry 2014;14:340.

13. Walford GA, Nelson WM, McCluskey DR. Fatigue, depression, and social adjustment in chronic fatigue syndrome. Arch Dis Child 1993;68:384-8.

14. Fombonne E, Wostear G, Cooper V, et al. The Maudsley long-term follow-up of child and adolescent depression. 1. Psychiatric outcomes in adulthood. Br J Psychiatry 2001;179:210-17. 
15. Wearden AJ, Dunn G, Dowrick C, et al. Depressive symptoms and pragmatic rehabilitation for chronic fatigue syndrome. Br J Psychiatry 2012;201:227-32.

16. White PD, Naish VA. Graded exercise therapy for chronic fatigue syndrome. Physiotherapy 2001;87:285-8.

17. Kempke S, Goossens L, Luyten $\mathrm{P}$, et al. Predictors of outcome in a multi-component treatment program for chronic fatigue syndrome. J Affect Disord 2010;126:174-9.

18. Flo E, Chalder T. Prevalence and predictors of recovery from chronic fatigue syndrome in a routine clinical practice. Behav Res Ther 2014;63:1-8.

19. Darbishire L, Seed P, Risdale L. Predictors of outcome following treatment for chronic fatigue. Br J Psychiatry 2005;186:350-1.

20. Matsuda Y, Matsui T, Kataoka K, et al. A two-year follow-up study of chronic fatigue syndrome comorbid with psychiatric disorders. Psychiatry Clin Neurosci 2009;63:365-73.

21. Schreurs KMG, Veehof MM, Passade L, et al. Cognitive behavioural treatment for chronic fatigue syndrome in a rehabilitation setting: effectiveness and predictors of outcome. Behav Res Ther 2011;49:908-13.

22. Prins J, Bleijenberg G, Rouweler EK, et al. Effect of psychiatric disorders on outcome of cognitive-behavioural therapy for chronic fatigue syndrome. Br J Psychiatry 2005;187:184-5.

23. RCPCH. Evidence Based Guideline for the Management of CFS/ME (Chronic Fatigue Syndrome/Myalgic Encephalopathy) in Children and Young People. Royal College of Paediatrics and Child Health, 2004.

24. Higgins JPT, Altman DG, Gøtzsche PC, et al. The Cochrane Collaboration's tool for assessing risk of bias in randomised trials. BMJ 2011;343:d5928.

25. Higgins JPT, Altman DG, Sterne JAC. Assessing risk of bias in included studies. Cochrane handbook for systematic reviews of interventions version 50, 2008.

26. Higgins JPT, Green S. Cochrane handbook for systematic reviews of interventions. Wiley Online Library, 2008.

27. Gordon BA, Knapman LM, Lubitz L. Graduated exercise training and progressive resistance training in adolescents with chronic fatigue syndrome: a randomized controlled pilot study. Clin Rehabil 2010;24:1072-9.

28. Chalder T, Tong J, Deary V. Family cognitive behaviour therapy for chronic fatigue syndrome: an uncontrolled study. Arch Dis Child 2002;86:95-7.

29. Lloyd S, Chalder T, Sallis HM, et al. Telephone-based guided self-help for adolescents with chronic fatigue syndrome: a non-randomised cohort study. Behav Res Ther 2012;50:304-12.

30. Kawatani J, Mizuno K, Shiraishi S, et al. Cognitive dysfunction and mental fatigue in childhood chronic fatigue syndrome-a 6-month follow-up study. Brain Dev 2011;33:832-41.

31. Gordon BA, Lubitz L. Promising outcomes of an adolescent chronic fatigue syndrome inpatient programme. J Paediatr Child Health 2009;45:286-90

32. Rimes KA, Goodman R, Hotopf M, et al. Incidence, prognosis, and risk factors for fatigue and chronic fatigue syndrome in adolescents: a prospective community study. Pediatrics 2007;119:e603-9.
33. van de Putte EM, Engelbert RH, Kuis W, et al. Alexithymia in adolescents with chronic fatigue syndrome. J Psychosom Res 2007;63:377-80.

34. Henderson TA. Valacyclovir treatment of chronic fatigue in adolescents. Adv Mind Body Med 2014;28:4-14.

35. Jason LA, Bell DS, Rowe K, et al. A pediatric case definition for myalgic encephalomyelitis and chronic fatigue syndrome. J Chron Fatigue Syndr 2006;13:1-44.

36. Denborough P, Kinsella S, Stevens J, et al. Evaluation of a multidisciplinary inpatient rehabilitation programme for adolescents with chronic fatigue syndrome. Australas Psychiatry 2003;11:319-24.

37. Browne T, Chalder T. Chronic fatigue syndrome. Psychiatry 2006;5:48-51

38. NICE. Depression in children and young people: psychological interventions for mild depression and pharmacological interventions for moderate to severe depression (update). 2015.

39. NICE. Depression in children and young people: identification and management in primary, community and secondary care. Excellence NloHaC. 2005.

40. Haig-Ferguson A, Tucker P, Eaton N, et al. Memory and attention problems in children with chronic fatigue syndrome or myalgic encephalopathy. Arch Dis Child 2009;94:757-62.

41. March J, Silva S, Petrycki S, et al. Fluoxetine, cognitive-behavioral therapy, and their combination for adolescents with depression: Treatment for Adolescents With Depression Study (TADS) randomized controlled trial. JAMA 2004;292:807-20.

42. Emslie GJ, Mayes T, Porta G, et al. Treatment of resistant depression in adolescents (TORDIA): week 24 outcomes. Am J Psychiatry 2010;167:782-91.

43. Hammad TA, Laughren T, Racoosin J. Suicidality in pediatric patients treated with antidepressant drugs. Arch Gen Psychiatry 2006;63:332-9

44. Vercoulen JHMM, Hoofs MPE, Bleijenberg G, et al. Randomised double-blind, placebo-controlled study of fluoxetine in chronic fatigue syndrome. Lancet 1996;347:858-61.

45. Wearden AJ, Morriss RK, Mullis R, et al. Randomised, double-blind, placebo-controlled treatment trial of fluoxetine and graded exercise for chronic fatigue syndrome. Br J Psychiatry 1998;172:485-90.

46. Amsterdam JD, Shults J, Rutherford N. Open-label study of s-citalopram therapy of chronic fatigue syndrome and co-morbid major depressive disorder. Prog Neuropsychopharmacol Biol Psychiatry 2008;32:100-6.

47. Nijhof SL, Bleijenberg G, Uiterwaal CS, et al. Fatigue in teenagers on the interNET - the FITNET Trial. A randomized clinical trial of web-based cognitive behavioural therapy for adolescents with chronic fatigue syndrome: study protocol. [ISRCTN59878666]. BMC Neurol 2011;11:23.

48. Nijhof SL, Priesterbach LP, Bleijenberg G, et al. Functional improvement is accompanied by reduced pain in adolescent chronic fatigue syndrome. Pain Med 2013;14:1435-8.

49. Moher D, Liberati A, Tetzlaff $\mathrm{J}$, et al. Preferred reporting items for systematic reviews and meta-analyses: the PRISMA statement. PLoS Med 2009;6:e1000097. 